\title{
A REVIEW ON FRIEDREICH ATAXIA, A NEURODEGENERATIVE DISORDER
}

\author{
Soni Dhruvkumar M.
}

Bombay College of Pharmacy, Kalina, Santacruz (East), Mumbai, India 400095

\begin{abstract}
The present report discusses about the clinical trial requirements for Friedreich ataxia disease such as inclusion and exclusion criteria for the patients,primary/secondary outcome measuresrequired for assessing the efficacy of therapies viarating scales, physical activity tests, biomarkersand number of subjects/patients to be enrolled in each phase of the clinical trials of Friedreich ataxia (F.A.). These parameters have been selected from the ongoing and completed clinical trials for F.A. as reported in Clinical trials.gov and Friedreich Ataxia Research Alliance (FARA) official website. A total of 33 clinical trialdetails werereviewed for compilation of the above mentioned parameters. For the purpose of this report, the most useful and most commonly assessedprimary/secondary outcome measureswith respect to efficacy as well as inclusion and exclusion criteria have been selected and are being cited in this review. The outcome measures for the purpose of efficacy trials can broadly be classified as primary and secondaryoutcome measures and in each category, subclasses are being presented in the order of their priority as determined by their usefulness and common occurrence in all trials mentioned. These outcome measuresincludeRating Scales for Friedreich Ataxia, Physical Activity Tests and Biomarkers, evaluation of Cardiac functionality viz. left ventricular wall mass, non-invasive measures of systolic and diastolic ventricular function, echocardiography and immunogenicity.The genetic predisposition of Friedreich ataxia (epigenetics) leading to the pathogenesis of the disease is also discussed in this report. Based on above primary and secondary outcomes measures and inclusion and exclusion criteria, a tabular representation of the ongoing/ completed clinical trials representing the efficacy studies of the test molecules and the patient involvements in each clinical trial is also been listed. Various aspects of clinical trialsneeded for assessing ataxic stage in Friedreich ataxia disease is been reviewed in this article.
\end{abstract}

Key words:Friedreich ataxia, Friedreich Ataxia Research Alliance (FARA), Inclusion and Exclusion criteria, primary and secondary outcome measures, rating scales, biomarkers, physical activity tests.

\section{INTRODUCTION}

\section{Friedreich Ataxia (FA)}

FRDA is a common autosomal recessive neurodegenerative disease (1/50,000 live births) characterized by a progressive gait and limb ataxia with lack of tendon reflexes in the legs, dysarthria and pyramidal weakness of the inferior limbs ${ }^{i}$. The term "dystaxia" is a rarely used synonym for F.A. Hypertrophic Cardiomyopathy is also observed in most FRDA patients. The condition is named after the German physician NikolausFriedreich, who first described it in the 1860s.Friedreich ataxia is an orphan disease having Orphanet orphan number ORPHA95. FARA (Friedreich Ataxia Research Alliance) is an organization dedicated towards the conducting active research for the diagnosis and treatment of Friedreich ataxia. $^{1}$

\section{Genetic Predisposition of Friedreich Ataxia (Epigenetics)}

Mutations in the $F X N$ gene cause Friedreich ataxia. This gene provides instructions for making a protein called frataxin. One region of the $F X N$ gene contains a segment of DNA known as a GAA trinucleotide repeat. This segment is made up of a series of three DNA building blocks (one guanine and two adenines) that appear multiple times in a row. Normally, this segment is repeated 5 to 33 times within the $F X N$ gene.In people with Friedreich ataxia, the GAA segment is repeated 66 to more than 1,000 times. The length of the GAA trinucleotide repeat appears to be related to the age at which the symptoms of Friedreich ataxia appear. People with GAA segments repeated fewer than 300 times tend to have a later appearance of symptoms (after age 25) than those with larger GAA trinucleotide repeats. The abnormally long GAA trinucleotide repeat disrupts the production of frataxin, which severely reduces the amount of this protein in cells. Certain nerve and muscle cells cannot function properly with a shortage of frataxin leading to the characteristic signs and symptoms of Friedreich ataxia. ii $^{\text {. }}$ 


\section{Pharmacotherapy of Friedreich ataxia (F.A.)}

According to the ongoing/completed clinical trials, currently there are around a dozen of drug molecules which are being evaluated for their efficacy against F.A. at different stages of clinical trials.However, few molecules are already been approved drugs for F.A. The results of treating ataxia in F.A. have generally been disappointing. No therapeutic measures are known to alter the natural history of the neurological disease. Standard treatment is administered for heart failure, arrhythmias, and diabetes mellitus. In one of case reports, high-dose propranolol has been described with reduction in thickness of the septal and posterior left ventricular walls and with complete normalization of diffuse electrocardiographic repolarization

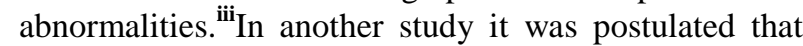
therapeutic efforts should be focused on an approach that combines iron removal from mitochondria with a treatment that increases cytosolic iron levels to maximize residual frataxin expression in patients with F.A. ${ }^{\text {iv }}$

The other therapies that have been widely investigated are as follows:

\section{5-Hydroxytryptophan}

5-Hydroxytryptophan is a serotonin precursor that has been used for a decade or more to treat various forms of ataxia with mixed results. ${ }^{\mathbf{v}}$ This drug was known to suppress post-hypoxic action myoclonus. The rationale for use of the drug was that F.A. may be causedin part due to cerebellar deficiency of serotonin. The results of a double-blind, cross-over study demonstrated that the levorotatory form of 5-hydroxytryptophan was able to significantly modify the cerebellar symptoms in patients with F.A.; however, the effect was only partial and not clinically major.A study by Wessel Stabilization of posture in patients receiving long-term treatment with 5-hydroxytryptophan was also demonstrated ${ }^{\mathbf{v i}}$ and a clear deterioration in patients who did not receive the treatment. This form of treatment required further study to validate proof of concept.

\section{Coenzyme Q}

Coenzyme Q is an antioxidant that buffers free radicals that are generated by excess of mitochondrial iron. A combined coenzyme Q (400 mg/d) and vitamin E (2100 IU/d) therapy has been used which showed delayed progression of certain clinical features and a significant improvement in cardiac function ${ }^{\text {vii }}$. Experimental studies are underway to evaluate the use of coenzyme Q derivatives in limiting the toxicity of iron to mitochondrial structures.

\section{Idebenone}

Idebenone has been used as therapy for Friedreich ataxia for more than a decade. At present, several studies have assessed the influence of therapy on neurologic or cardiac function. The effect of intermediate-dose idebenone $(20 \mathrm{mg} / \mathrm{kg} / \mathrm{d})$ on quality of life and neurologic function was assessed in a recent

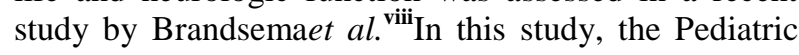
Quality of Life Inventory, the International Cooperative
Ataxia Rating Scale, and an Activities of Daily Living Scale before initiation of idebenone therapy and after 1 year of therapy were assessed. The scores on the Pediatric Quality of Life Inventory were universally worse after 1 year and correlated with decreased activities of daily living scores. However, there was a trend toward improved total, emotional, social, and school components of quality of life scores after 1 year of idebenone therapy. There was no statistically significant change in Pediatric Quality of Life Inventory scores between baseline and 1 year of idebenone therapy. Functional ability, as measured by activities of daily living scores, seems to have the most influence on the physical quality of life. Prior randomized, doubleblind, placebo-controlled intervention trial by Lynch et al. did not reveal any statistically significant difference between the placebo and idebenone on the International Cooperative Ataxia Rating Scale. ${ }^{\text {ix }}$

\section{Interferon gamma}

Tomassiniet al. (2012) have revealed that in vivo treatment with interferon-gamma increases frataxin expression in dorsal root ganglia neurons, prevents their pathological changes, and ameliorates the sensorimotor performance in F.A. mice. These results disclose new roles for interferon-gamma in cellular metabolism and have direct implications for the treatment of F.A. ${ }^{\mathrm{x}}$ Pandolfoet al. have recently reviewed the utility of deferiprone with specific regard to its iron chelating properties and clinical benefits. ${ }^{\mathbf{x i}}$

\section{Primary and Secondary Outcome Measurements}

A summary of the clinical trials from clinicaltrials.gov and FARA is been compiled in Table 1.2. From the clinical trial summary, the primary and secondary outcome measures which are most commonly used in these efficacy studies are been discussed below in order of their significance for evaluating efficacy against F.A.

\section{A.) Rating Scales ${ }^{\mathrm{xii}}$ \\ i. Friedreich Ataxia Rating Scale (FARS) ${ }^{2}$}

The Friedreich Ataxia Rating Scale (FARS) is made up of a measure of ataxia, activities of daily living subscale (ADL) and a neurological subscale. These scales also include the $8 \mathrm{~m}$ walk at maximum speed $(8 \mathrm{MW})$, the 9hole peg test (9HPT), PATA rate and Low-Contrast Letter Acuity Test (LCAT).

* Strengths:FARS scores correlate significantly with functional disability, activities of daily living scores and disease duration. FARS has a large effect size and requires fewer patients for an equivalently powered study.

* Weaknesses:This scale captures a particular dimension of neurologic function in F.A., so as a composite measure, it is not good enough to predict disease status.

ii. Scale For Assessment and Rating of Ataxia (SARA) ${ }^{\text {xiii,xiv, xv }}$ 
SARA is a clinical scale that is based on a semiquantitative assessment of cerebellar ataxia on an impairment level. SARA has eight items that are related to gait, stance, sitting, speech, finger-chase test, nosefinger test, fast alternating movements and heel-shin test. Although the cerebellum is directly involved in the coordination of eye movements, oculomotor functions are not considered, as the validation trials indicated that they are determined by other factors than appendicular and midline ataxia. SARA underwent a rigorous validation procedure involving three large multi-center trials in SCA and non-SCA ataxia patients, as well as controls.

\section{iii. International Cooperative Ataxia Rating Scale $\left(\right.$ ICARS) ${ }^{\mathrm{xvi}}$}

The proposed scale involves a compartmentalized quantification of postural and stance disorders, limb ataxia, dysarthria and oculomotor disorders, in order that a sub-score concerning these symptoms may be separately studied. The members of the Committee agreed upon precise definitions of the tests, to minimize inter-observer variations. The validation of this scale is under progress.

\section{B.) Physical Tests:}

Physical tests mainly correlate the stage of ataxia in Friedreich ataxic patients. Ataxia is a non-specific clinical manifestation implying dysfunction of the parts of the nervous system mainly cerebellumthat is involved in coordinatingmuscle movement. ${ }^{\text {xvii,xviii }}$ Several possible causes exist for these patterns of neurological dysfunction. Different physical tests are employed to assess the progression of F.A. in Friedreich ataxia patients. These tests are as follows:

1. 9-Hole Peg Test (HPT)

2. Timed 25-Foot Walk (T25FW)

3. Low Contrast Letter Acuity Test (LCLA)

4. Visual Assessment Scale (VAS)

\section{9-Hole Peg Test (HPT) ${ }^{\mathrm{xix}, \mathrm{xx}, \mathrm{xxi}}$}

This simple test of manual dexterity records the time required for the participant to accurately place and remove nine plastic pegs into a plastic pegboard. The protocol includes 1 practice and 1 timed trial with each hand. Raw scores are recorded as time in seconds that it takes the participant to complete the task with each hand (a separate score for each) (Figs.I a)

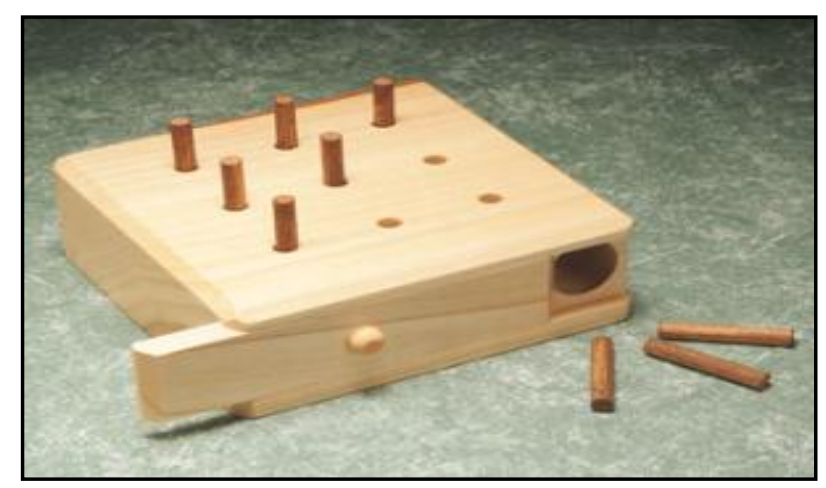

Figure I: 9-Hole Peg Test (HPT)

\section{Timed 25 Foot Walk Test (T-25 FW)}

In this test the subject should walk 7.62 meters ( 25 feet) as quickly, but safely, as possible without running. The path on which the test is walked, such as a hallway, should be clearly marked and free of obstructions. Patients are permitted to use their own assistive device or, in the case of a clinical trial or serial study, the best assistive device that might be necessary. The timedwalk test should be performed twice, the time being recorded in seconds, starting as the lead foot passes the start line and ending as the lead foot passes the finish line. ${ }^{\text {xii, } x x i i i}$

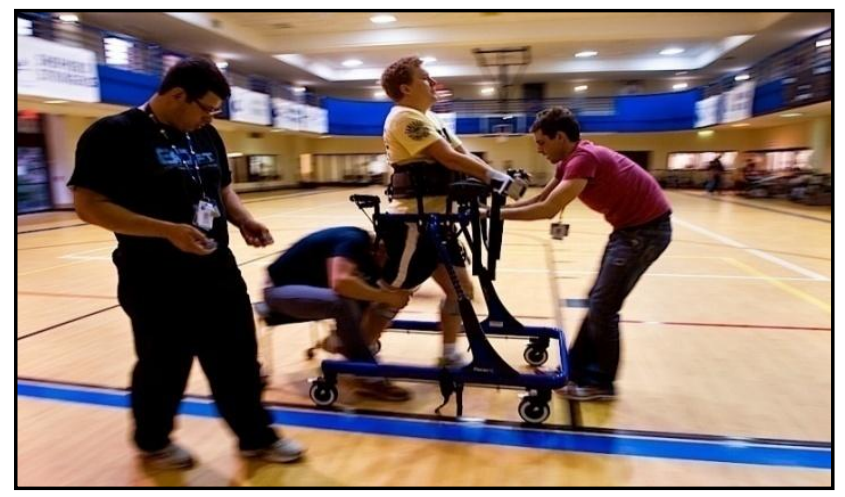

Figure II: Time 25 foot walk test

\section{C.)Biomarkers:}

Frataxin, 8-Hydroxy-2-deoxyguanosine, Peroxides and Plasma F2- isoprostanes are some of the biomarkers used for assessing the clinical state of Friedreich ataxia. These are discussed in more detail below.

\section{a) Frataxin:}

Friedreich ataxia (FRDA) is a neurodegenerative disease caused by mutations in the frataxin (FXN) gene, resulting in reduced expression of the mitochondrial protein frataxin.Frataxin is localized in the mitochondrion. The function of frataxin is not entirely clear, but it seems to be involved in assembly of ironsulfur clusters. It has been proposed to act as either an iron chaperone or an iron storage protein. Lateral flow "dipstick" immunoassay for the measurement of frataxin protein in multiple peripheral cell types is employed as a determination technique for FRATAXIN levels. The dipstick assay showed utility in a variety of clinical applications, including preliminary diagnosis of atypical FRDA patients, analysis of longitudinal frataxin measurements, correlations with changes in neurological severity. ${ }^{\text {xiv }}$ This technique does not require isolation or purification of mitochondria. ${ }^{\mathbf{x v}}$

Lymphocytes are mainly used for assessing peripherialfrataxin levels. The importance of lymphocytic frataxin levels in the assessment of friedreich ataxia are noted as under:

i. Lymphocytes are suitable for large scale clinical trials,

ii. Lymphocytes show higher frataxin levels as compared to buccal cells in controls, known carriers and patients. Coefficient of variation is fewer amongst the control individuals. ${ }^{\text {xxi }}$ 
iii. Highest levels of frataxin in blood are found in erythrocytes. As erythrocytes are not useful for frataxin assessment in many clinical trial situations, PBMCs (Peripherial blood mononuclear cells) and buccal swabs have frataxin levels equivalent to those of whole blood. In addition, a dose-dependent increase in frataxin was observed when PBMCs isolated from patient blood were treated with Histone Deacetylase Inhibitors (HDACi). ${ }^{\text {xxii }}$

iv. Frataxindownregulation is associated with robust changes in gene expression in PBMCs (lymphocytes), providing pathogenetic insights and a core subset of genes that, if verified in vivo, could be used as a peripheral biomarker. $^{\text {xxviii }}$

\section{b) 8-Hydroxy-2-Deoxyguanosine:}

DNA is subject to constantoxidative damage from endogenous oxidants. The oxidized DNA is continuously repaired and the oxidized bases are excreted in the urine. A simple routine analytical procedure is described for urinary 8-hydroxy-2'deoxyguanosine, an oxidative DNA damage adduct, as an indicator of oxidative damage in humans and rodents. $^{\text {xxix }}$ This adduct was purified from human urine and characterized. The described assay employs a series of solid phase extraction steps that separate 8-hydroxy2'-deoxyguanosine from other urinary constituents, followed by analysis by gradient reversed-phase HPLC coupled to a dual electrode high-efficiency electrochemical detection system. Analysis of urine from three species by this method indicated that mice excrete approximately 3.3-fold more 8-hydroxy-2'deoxyguanosine than humans (582 vs. 178 residues per cell per day), a result that supported the proposal that oxidative damage to DNA increases in proportion to that of species-specific basal metabolic rates. ${ }^{\mathbf{x x}}$

\section{c) Peroxides:}

Frataxin and iron-sulphur cluster proteins deficiency causes accumulation of molecular iron in the cytoplasm of neurons. The increase in the amount of molecular iron causes production of reactive oxidative species mainly superoxides and peroxides by Fenton chemical reactions. These reactive oxidant species cause induction in the activity of antioxidant enzymes mainly superoxide dismutase (SOD) and Glutathione reductase (GR). The presence of these antioxidant enzymes are quantified using enzyme linked immunosorbent assay (ELISA). ${ }^{\text {xxxi,xxxii }}$

\section{d) Plasma F2 Isoprostanes:}

F2-isoprostanes are prostaglandin F2-like compounds that are known to be formed in vivo by free radical oxidation of arachidonyl-containing lipids inside the cell and when they come into the plasma, their plasma levels have been suggested as indicators of in vivo oxidative stress. As F2-isoprostanes are potent vasoconstrictors and can modulate platelet aggregation, their formation has important implications in the genesis of cardiovascular disease. ${ }^{\text {xxxii }}$

\section{Inclusion and Exclusion criteria}

Further, based on the clinical trials as listed in Table 1.2, the most common inclusion and exclusion criteria, specific for F.A. efficacy assessment trials, are summarized below. Other general inclusion and exclusion criteria, which are common in most of the clinical trials are not being discussed here.

\section{Inclusion Criteria:}

1. Diseased individual: Patient with Friedreich ataxia and has had a genetic test demonstrating > 400 G.A.A trinucleotide repeats on shorter of the two frataxin alleles, [A detailed analysis of such diagnosis is given in the Genetic predisposition section of Friedreich ataxia-epigenetics].

2. Scale for Assessment and Rating of Ataxia (SARA) (stance) subscore of $<=6$,

3. SARA (gait) subscore of $<=6$,

\section{Exclusion Criteria:}

1. Patients unable to stand up even with support (Wheelchair bound patients),

2. Iron deficiency defined as ferritin levels below the reference range for age- and sex-matched controls,

3. Unable to complete $\mathrm{T} 25 \mathrm{FW}$ and with score $>5$ minutes in the 9HPT. (Subjects who can complete $\mathrm{T} 25 \mathrm{FW}$ or with a score $\leq 5$ minutes in the $9 \mathrm{HPT}$ will be allowed to enroll if the score has not doubled compared to screening.)

4. Subjects with a history of seizures.

Further, regarding the number of subjects/ patients in these clinical trials have also been compiled according to the clinical trial phases. Table 1.1 provides a range of the enrollment in such studies related to F.A. according to the stages in the clinical trial, however, this range is very broad and may vary with the scope of the trial, therefore, the enrollments in individual trials from Table 1.2 may please be referred for more specific information.

Table 1.1: Range Of Patient Enrollment According To Clinical Trial Phases

\begin{tabular}{|l|l|l|}
\hline $\begin{array}{l}\text { Sr. } \\
\text { No. }\end{array}$ & Phases & $\begin{array}{l}\text { Range of Patient } \\
\text { Enrollments }\end{array}$ \\
\hline 1. & I (Interventional) & $16-100$ \\
\hline 2. & II (Interventional) & $12-87$ \\
\hline 3. & III (Interventional) & $40-232$ \\
\hline 4. & IV (Interventional) & 01 \\
\hline 5. & OBSERVATIONAL & $30-40$ \\
\hline 6. & INTERVENTIONAL & $20-52$ \\
\hline
\end{tabular}


Table 1.2: Test Drug Molecules According To Ongoing and Completed Clinical Trials:

\begin{tabular}{|c|c|c|}
\hline $\begin{array}{l}\text { Sr. } \\
\text { No. }\end{array}$ & Test Drugs & Title, Enrollments and Clinical Trial Phase \\
\hline 1. & $\begin{array}{l}\text { Resveratrol } \\
\text { (Antioxidant, neuroprotective) } \\
\text { (Michio Takaokaet.al) }\end{array}$ & $\begin{array}{l}\text { A Study of Resveratrol as Treatment for F.A. (30) } \\
\text { (Phase I and II interventional) }\end{array}$ \\
\hline 2. & $\begin{array}{l}\text { Idebenone } \\
\text { (Antioxidant) } \\
\text { (Takeda Chemicals Ltd, Japan) }\end{array}$ & $\begin{array}{l}\text { 1. Idebenone to Treat F.A. (51) (Phase II-Interventional), } \\
\text { 2. Study to Assess the Efficacy, Safety and Tolerability of Idebenone in the } \\
\text { Treatment of F.A. (IONIA) (70), (Phase III-Interventional) } \\
\text { 3. Patient Reported Outcomes in F.A. Patients After withdrawal From } \\
\text { Treatment With Idebenone (PROTI) (80),(Phase III-Interventional) } \\
\text { 4. A Study of Efficacy, Safety and Tolerability of Idebenone in the } \\
\text { Treatment of F.A. (FRDA) Patients (MICONOS) (232), } \\
\text { (Phase III-Interventional) }\end{array}$ \\
\hline 3. & $\begin{array}{l}\text { Epoetinalfa } \\
\text { (Increases frataxin levels) } \\
\text { (Boesch S. et.al) }\end{array}$ & $\begin{array}{l}\text { 1.Efficacy Study of Epoetin Alfa in F.A. (FRIEMAX) (56) (Phase II- } \\
\text { Interventional) } \\
\text { 2.Efficacy of Epoetin Alfa in Patients with F.A. (10) (Phase II } \\
\text { Interventional) }\end{array}$ \\
\hline 4. & $\begin{array}{l}\text { EPI-743 } \\
\text { (Improves visual function) } \\
\text { (Edison Pharmaceutical Inc.) }\end{array}$ & $\begin{array}{ll}\text { 1. } & \text { EPI-743 in F.A. Point Mutations (04) (Phase II-Interventional), } \\
\text { 2. } & \begin{array}{l}\text { Safety and Efficacy of EPI-743 in Patients with F.A. (60) } \\
\text { (Phase II-Interventional), }\end{array} \\
\text { 3. } & \begin{array}{l}\text { EPI-743 for Mitochondrial Respiratory Chain Diseases (87) } \\
\text { (Phase II-Interventional). }\end{array}\end{array}$ \\
\hline 5. & $\begin{array}{l}\text { Varenicline(Nicotinic acetylcholine } \\
\text { receptor agonist-Reduces pain } \\
\text { associated with the symptoms.) } \\
\text { (Dr. Zesiewiczet.al) }\end{array}$ & $\begin{array}{l}\text { Pilot Study of Varenicline (Chantix®) in the Treatment F.A. (28) Phase II } \\
\text { Interventional }\end{array}$ \\
\hline 6. & $\begin{array}{l}\text { EGb-761 } \\
\text { (Antioxidant) } \\
\text { (Ipsen) }\end{array}$ & $\begin{array}{l}\text { Efficacy of EGb761 in Patients Suffering From F.A. (22) (Phase-II } \\
\text { Interventional), }\end{array}$ \\
\hline 7. & $\begin{array}{l}\text { Alpha tocopherolquinone-A0001 } \\
\text { (Antioxidant) } \\
\text { (Penwest Pharmaceuticals Co.) }\end{array}$ & $\begin{array}{l}\text { Safety and Efficacy Study of A0001 in Subjects With F.A. (42)(Phase II- } \\
\text { Interventional), }\end{array}$ \\
\hline 8. & $\begin{array}{l}\text { Nicotinamide(Upregulatesfrataxingene } \\
\text { expression) } \\
\text { (Chan and Torres et.al) }\end{array}$ & Effect of Nicotinamide (Vitamin B3) in F.A. (20) (Phase II-Interventional), \\
\hline 9. & $\begin{array}{l}\text { Interferon gamma-1b } \\
\text { (Increases Frataxin levels) } \\
\text { (Roberto Testi and Barbara } \\
\text { Tomassiniet.al) }\end{array}$ & Interferon Gamma-1b in FRDA (12) (Phase II-Interventional), \\
\hline 10. & $\begin{array}{l}\text { Ironchelating intervention. } \\
\text { (Antioxidant) }\end{array}$ & Iron-Chelating Therapy and F.A. (15) (Phase I/II- Interventional) \\
\hline 11. & $\begin{array}{l}\text { Pioglitazone (ACTOS) } \\
\text { (PPAR-gamma agonist) } \\
\text { (Restores Normal Superoxide } \\
\text { dismutase function.) } \\
\text { (Massimo Pandolfoet.al) } \\
\end{array}$ & $\begin{array}{l}\text { Effect of Pioglitazone Administered to Patients With F.A.: Proof of Concept } \\
\text { (ACTFRIE) (40) (Phase III-Interventional). }\end{array}$ \\
\hline 12. & $\begin{array}{l}\text { Riluzole(Rilutek by Sanofi-Aventis) } \\
\text { (Neuroprotective via inhibition of } \\
\text { NMDA receptor) }\end{array}$ & $\begin{array}{l}\text { Efficacy of Riluzole in Hereditary Cerebellar Ataxia (60) (Phase II- } \\
\text { Interventional). }\end{array}$ \\
\hline 13. & $\begin{array}{l}\text { Bupropion+ } \\
\text { citalopram, } \\
\text { Bupropion+ } \\
\text { Placebo, } \\
\text { Placebo+ } \\
\text { Citalopram, } \\
\text { Placebo+ } \\
\text { Placebo. } \\
\text { (Antidepressant and } \\
\text { Antipsychotic activity) }\end{array}$ & $\begin{array}{l}\text { An Objective Double-blind Evaluation of Bupropion and } \\
\text { Citalopram in an Individual With F.A. (1) } \\
\text { (Phase IV-Interventional) }\end{array}$ \\
\hline 14. & $\begin{array}{l}\text { Deferiprone } \\
\text { (Antioxidant)(Arnold Munnichet.al, } \\
\text { Apotex Technologies Inc.) }\end{array}$ & $\begin{array}{l}\text { Efficacy and Safety of the Iron ChelatorDeferiprone in Parkinson's disease } \\
\text { (FAIR-PARK-I) (40) } \\
\text { (Phase II-Interventional) }\end{array}$ \\
\hline
\end{tabular}


V. Institutions Working for the Research and Treatment of Friedreich Ataxia:

\section{The Collaborative Clinical Research Network in Friedreich's Ataxia(CCRN in FA):}

It is an international network of clinical research working together for advance treatments and clinical care for individuals with Friedreich's ataxia. The network collaborates with pharmaceutical companies, government agencies and other research centers and the patient community to facilitate clinical research and trials needed to identify new therapies. ${ }^{\text {xxiv }}$

\section{FARA (Friedreich Ataxia Research Alliance)}

(FARA) is a national, public, 501(c)(3), non-profit, taxexempt organization dedicated towards curing Friedreich's ataxia (FA) through research. FARA grants and activities provide support for basic and translational FA research, pharmaceutical/ biotech drug development, clinical trials, and scientific conferences. ${ }^{\mathbf{x x x}}$ FARA being a multifunctional organization which endorses following features:

\section{i. FARA Patient Registry:}

The FARA patient registry is the worldwide registry of Friedreich ataxia patients. Over 1800 Friedreich ataxia patients, from across the United States and internationally, have registered their demographic and basic clinical information in this database. ${ }^{\mathbf{x x v i}}$

\section{ii. FARA's Grant Program:}

FARA supports research through funding competitive grants, promoting collaboration among scientists, advocating for public-private partnerships that support drug discovery, drug development and clinical research and hosting open forums for leading scientists to share their insights, ideas and challenges to advancing treatments for F.A.

In addition to General Research Grants, FARA offers named awards for projects fitting specific criteria: (1) Cardiac Research; (2) Translational Research; and (3) International Collaborative Research.The proposed research must fall within FARA's Grant Program Priorities.

Table 1.3: Grant Types, Deadlines and Budget Limits under FARA ${ }^{\text {xxxii }}$

\begin{tabular}{|c|c|c|c|}
\hline Grant Type & $\begin{array}{l}\text { Letter of Intent } \\
\text { (LOI) Deadlines }\end{array}$ & $\begin{array}{l}\text { Application } \\
\text { Deadlines }\end{array}$ & $\begin{array}{l}\text { Maximum Budget } \\
\text { (in US dollars) }\end{array}$ \\
\hline General Research Grant & $\begin{array}{l}\text { Feb } 1 \\
\text { July } 15\end{array}$ & $\begin{array}{l}\text { April } 1 \\
\text { Sept } 15\end{array}$ & $\begin{array}{l}\$ 150,000 \text { per year } \\
\text { for } 1 \text { or } 2 \text { years }\end{array}$ \\
\hline $\begin{array}{c}\text { Keith Michael Andrus Cardiac } \\
\text { Research Award }\end{array}$ & January 15 & March 1 & $\begin{array}{l}\$ 150,000 \text { per year } \\
\text { for } 1 \text { or } 2 \text { years }\end{array}$ \\
\hline $\begin{array}{l}\text { Phillip Bennett and Kyle Bryant } \\
\text { Translational Research Award }\end{array}$ & May 15 & July 15 & $\begin{array}{l}\$ 250,000 \text { per year } \\
\text { for } 1 \text { or } 2 \text { years }\end{array}$ \\
\hline $\begin{array}{l}\text { Bronya J. Keats International } \\
\text { Research Collaboration Award }\end{array}$ & May 15 & July 15 & $\begin{array}{l}\$ 200,000 \text { per year } \\
\text { for } 1 \text { or } 2 \text { years }\end{array}$ \\
\hline
\end{tabular}

FARA, Ataxia UK and GoFARalso invite proposals for projects to develop biomarkers by non-invasive approaches for evaluating the molecular and pathological features of affected neurons in Friedreich's ataxia patients. ${ }^{\text {xxxviii }}$ Grant Program Review and Decision Process ${ }^{\mathrm{xx} x i x}$ and Grant Program Reporting Requirements ${ }^{3}$ are elucidated in detail in the cited reference.

\section{Additional Grant-Making Organizations:}

\section{Non-Profit Organizations}

- National Ataxia Foundation

- Muscular Dystrophy Association

- Ataxia UK

- FARA - Australasia

- American Heart Association

US Government Agencies

\section{NIH}

Principle concern of the NIH is to invest tax dollars wisely and to beentrusted for the support and conduct of vital biomedical research.

\section{Conclusion:}

Severe motor dysfunction in the pathophysiology of the disease is found to be highly devastating and scientists throughout the globe are aiming at reducing both the central genetic abnormality and the peripherial ataxic symptoms.Several test drug molecules are currently being evaluated at different stages of clinical trials for treatment ofcentral hyperoxidative state and peripherial symptoms of Friedreich ataxia. However, molecules which treat the genetic defect of FXN gene in Friedreich ataxia form the present forefront treatment modality for Friedreich ataxia. For assessing the efficacy of the test drug molecules, primary outcome measures are being constructed which includes various rating scales viz. FARS, SARA and ICARS, physical activity tests viz. 9-Peg hole test and Timed 25 foot walk test (T25FWT), Biomarkers for assessing the stage of disease viz. frataxin, 8-Hydroxy-2-deoxyguanosine, peroxidase, Plasma F2-Isoprostanes are also been ISSN: 2250-1177 
evaluated. Changes in these outcome measures after the test drug therapy, are been primarily assessed in ongoing and completed clinical trials. Secondary outcome measures including cardiomegaly, blood glucose tolerance and visual changesare also been assessed.Friedreich Ataxia Research Alliance (FARA) is a non-profit organization working for rehabilitation and treatment of Friedreich ataxia patients. FARA maintains a huge patient registry. These patients are then employed for the conduct of clinical trials of various test molecules at various phases of clinical trials. FARA in addition to other organizations, provide

\section{REFERENCES}

1. Harding AE, Friedreich's ataxia: a clinical and genetic study of 90 families with an analysis of early diagnostic criteria and intra - familial clustering of clinical features, Brain (1981) 104 (3): 589-620.

2. www.curefa.org/

3. Genetic Home Reference (Your Guide to Understanding Genetic Conditions), A Service of U.S. National Library of Medicine.

4. Kosutic J et al., High-dose beta-blocker hypertrophic cardiomyopathy therapy in a patient with Friedreich ataxia,PediatrCardiol. Sep-Oct 2005;26(5):727-30.

5. Li K et al., Iron-dependent regulation of frataxin expression: implications for treatment of Friedreich ataxia,Hum Mol Genet. Aug 1 2008; 17(15):2265-73.

6. Trouillas Pet al., Levorotatory form of 5-hydroxytryptophan in Friedreich's ataxia. Results of a double-blind drug-placebo co-operative study,Arch Neurol. May 1995; 52(5):456-60.

7. Currier RD, A Treatment for Ataxia,Arch Neurol. 1995; 52(5):449.

8. Parkinson MHet al., Co-enzyme Q10 and idebenone use in Friedreich's ataxia, J.Neurochem. 2013 Aug;126 Suppl. $1: 125-41$

9. Brandsema JFet al., Intermediate-dose idebenone and quality of life in Friedreich ataxia. Pediatr Neurol. May 2010;42(5):338-42.

10. Lynch DRet al., A Phase 3, Double-blind, Placebo-Controlled Trial of Idebenone in Friedreich Ataxia.,Arch Neurol. Aug 2010;67(8):941-7.

11. Tomassini Bet al., Interferon gamma upregulatesfrataxin and corrects the functional deficits in a Friedreich ataxia model,Hum Mol Genet., Jul 1, 2012; 21(13): 2855-2861.

12. Pandolfo Met al.,Deferiprone for the treatment of Friedreich's ataxia. J Neurochem. Aug 2013;126 Suppl 1:142-6.

13. Saute JAet al., Ataxia rating scales-psychometric profiles, natural history and their application in clinical trials, Cerebellum. 2012 Jun; 11(2):488-504.

14. www.commondataelements.ninds.nih.gov/Doc/NO/.Friedreic hs_Ataxia_Rating_Scale_NOC_Public_Domain.pdf.

15. www.ataxia-studygroup.net/html/about/ataxiascales/sara/SARA.pdf

16. T. Schmitz-Hübschet al., Scale for the assessment and rating of ataxia, Neurology June 13, 2006 vol. 66 no. 11 1717-1720

17. Yabe Iet al., Usefulness of the Scale for Assessment and Rating of Ataxia (SARA), J Neurol Sci., 2008 Mar 15; 266(12):164-6.

18. Trouillas Pet al., International Cooperative Ataxia Rating Scale for pharmacological assessment of the cerebellar syndrome. The Ataxia Neuropharmacology Committee of the World Federation of Neurology, J Neurol Sci.1997 Feb 12; 145(2):205-11.

19. http://www.ataxia.org/pdf/Ataxia_Classifications.pdf

20. CosséeM et al., Friedreich's ataxia: Point mutations and clinical presentation of compound heterozygotes, Annals of Neurology, Volume 45, Issue 2, pages 200-206, February 1999

21. www.nihtoolbox.org/WhatAndWhy/Motor/Dexterity/Pages/N IH-Toolbox-9-Hole-Pegboard-Dexterity-Test.aspx. various grants for conducting research in the field of Friedreich ataxia pathophysiology and clinical improvement of the disease condition. Thus, knowing the genetic predisposition of Friedreich ataxia and development of various test molecules which are found to improve symptoms and the disease progression of Friedreich ataxia, the morbidity rate of the disease could be improved and the mortality rate of the patient could then be reduced.

\section{CONFLICT OF INTEREST}

Author declares no conflict of interest.

22. www.rehabmeasures.org/PDF\%20Library/Nine\%20Hole\%20 Peg\%20Test\%20Instructions.pdf

23. www.rehabmeasures.org/Lists/RehabMeasures/DispForm.asp $\mathrm{x} ? \mathrm{ID}=925$

24. www.msforum.net/Site/ViewPDF/ViewPDF.aspx?ArticleID= 4006D6D0E679448591C96486FA163226n\&doctype=Article

25. www.nationalmssociety.org/ms-clinical-carenetwork/researchers/clinical-study-measures/t25fw/index.aspx

26. Deutsch E., "Measuring biomarkers of Friedreich ataxia: Implications for clinical research" (January 1, 2012).

27. Willis JHet al.., Lateral-flow immunoassay for the frataxin protein in Friedreich's ataxia patients and carriers, Mol. Genet. Metab., 94 (2008) 491-497.

28. Deutsch Eet al., A rapid, noninvasive immunoassay for frataxin: Utility in assessment of Friedreich ataxia, Mol Genet Metab., 2010 Oct-Nov; 101(2-3): 238-245.

29. Plasterer HLet al., Development of Frataxin Gene Expression Measures for the Evaluation of Experimental Treatments in Friedreich's Ataxia, May 17, 2013 DOI: 10.1371/journal.pone.0063958.

30. Giovanni Cet al., A gene expression phenotype in lymphocytes from friedreich ataxia patients, Annals of Neurology, Volume 70, Issue 5, pages 790-804, November 2011.

31. Schulz JB, Oxidative stress in patients with Friedreich ataxia, Neurology December 12, 2000 vol. 55 no. 11 1719-1721.

32. Ames BNet al., Urinary 8-hydroxy-2'-deoxyguanosine as a biological marker of in vivo oxidative DNA damage, Proc. Nall. Acad. Sci., USA Vol. 86, pp. 9697-9701, December 1989.

33. Vittorio $\mathrm{C}$, Oxidative stress, mitochondrial dysfunction and cellular stress response in Friedreich's ataxia, Journal of the Neurological Sciences, Volume 233, Issue 1 , Pages 145-162, 15 June 2005.

34. www.academia.edu/1745122/PROTEINS_AS_BIOMARKE RS_OF_OXIDATIVENITROSATIVE

35. www.jci.org/articles/view/117107/pdf/render

36. www.curefa.org/network.htm

37. www.curefa.org/about.html

38. www.curefa.org/registry.html

39. www.curefa.org/review.html

40. www.curefa.org/_pdf/FARA-AtaxiaUK-GoFARrfp092513.pdf

41. www.curefa.org/reporting.html

42. www.curefa.org/types-of-grants.html\#general 
